\title{
Physicochemical properties, antioxidant activity and phyto-nutritional composition of cold and hot pressed coconut oils
}

\author{
Idu MacDonald ${ }^{1 *}$, Ovuakporie-Uvo Oghale ${ }^{1}$, Omoregie Ehimwenma Sheena ${ }^{2}$ and Omosigho Mabel ${ }^{3}$ \\ ${ }^{1}$ Phytomedicine Research Group; Department of Plant Biology and Biotechnology, University of Benin, Benin City, PMB \\ 1154, Edo State, Nigeria. \\ 2 Department of Biochemistry, University of Benin, Benin City, PMB 1154, Edo State, Nigeria. \\ ${ }^{3}$ Department of Science Laboratory Technology, University of Benin, Benin City, PMB 1154, Edo State, Nigeria.
}

Publication history: Received on 14 August 2018; revised on 25 September 2018; accepted on 29 September 2018

Article DOI: https://doi.org/10.30574/gscbps.2018.5.1.0082

\begin{abstract}
Cold and hot pressed (CP and HP) coconut oils were subjected to physicochemical, antioxidant, fatty acid profile, vitamin composition and phytosterol analyses using standard analytical procedures. From the studies, both oils were soluble in non - polar solvent and liquid at room temperature. Hot pressed (HP) oil had a higher peroxide value, iodine value and saponification value while cold pressed oil had a higher free fatty acid and acid value. The antioxidant activity revealed that cold pressed oil had a better ferric reducing antioxidant potential (FRAP) and total antioxidant capacity (TAC) than the hot pressed oil. The major fatty acids (\%) found in both oil extracts were lauric acid (49.29 and 47.83), myristic acid (17.01 and 16.33), palmitic acid (9.53 and 9.94), capric acid (6.39 and 7.72) and caprylic acid (5.45 and 5.77) for cold and hot pressed oils respectively. Hot pressed oil had higher phytosterol content (102.79 mg/100g) however, the major phytosterol in both oils were $\beta$-sitosterol, $\Delta$-5-avenasterol and stigmasterol. Vitamins A, D, E and K were present in trace amount in both oil extracts. Hot pressed oil had a slightly better physicochemical characteristic and phyto-nutritional composition while cold pressed oil had a better antioxidant property. Considering the physicochemical properties, antioxidant activity and phyto-nutritional composition of cold and hot pressed coconut oils, their use in nutraceuticals and other industrial purposes should be encouraged.
\end{abstract}

Keywords: Coconut oil; Cold pressed; Hot pressed; Physicochemical; Phyto-nutritional composition

\section{Introduction}

Lipids are fat-like naturally occurring substances; insoluble in water but, soluble in non-aqueous solvents such as chloroform, hydrocarbons or alcohols. Lipids can be oils or fat depending on the degree of unsaturation of the fatty acid components at room temperature. Lipids can serve as food when calories demand by the body exceeds calories supply [1].

Coconut (Cocos nucifera) belongs to the Aracaceae family. It is a commercial crop in many tropical countries that plays an integral part in diets and livelihoods [2]. Coconuts and the oil content are believed to be rich in various constituent by traditionalists [3]. Kernel derived from coconut fruit is a rich source of oil. Coconut oil is largely consumed for domestic and industrial purposes which include cooking, bakery, confectionary, pharmaceutical and cosmetics [4]. Coconut oil has a natural sweet taste and contains $92 \%$ of saturated fatty acids (in the form of triglycerides); most of them (about 70\%) medium chain fatty acids (MCFAs) [5]. They are also resistant to peroxidation and have been reported to protect against heart disease as they lower the risk of atherosclerosis [6]. Gopala et al [5] have also highlighted the antiviral, antibacterial, antiplaque, antiprotozoal, healing, anti-inflammatory and anti-obesity effects of

\footnotetext{
${ }^{*}$ Corresponding author

E-mail address: mcdonald@uniben.edu
} 
Idu et al. / GSC Biological and Pharmaceutical Sciences 2018, 05(01), 056-066

medium chain fatty acids. Coconut oil maybe largely classified as refined (solvent extracted coconut oil) or unrefined (virgin coconut oil; hot pressed and cold pressed or copra coconut oil) according to their method of preparation [5]. Cold pressed as well as hot pressed coconut oils are extracted from the fresh wet coconut meat. However, while cold pressed coconut oil is prepared from crushed meat at room temperature, the latter is prepared by introducing a little heat as much as $40^{\circ} \mathrm{C}$. This enables the extractor get more oil from the coconut meat compared to the earlier mentioned. Thus, this study was designed to investigate the physicochemical properties, antioxidant activity and phyto-nutritional composition of cold pressed (CP) and hot pressed (HP) coconut oils in a bid to spot out any difference based on their mode of preparation.

\section{Materials and methods}

CP and HP coconut oils used in this study were gotten from Abuja, Nigeria to the Phytomedicine Research Unit of the University of Benin purely for research purpose. Prior the period of the research after the oils were delivered to the laboratory, the oils were kept at room temperature.

\subsection{Physicochemical analysis of coconut oils}

Specific gravity of the oils were determined using $\mathrm{W}=$ weight of sample specific gravity bottle according to the method described by Pearson [7]. Iodine (Wiji's method) and saponification values were determined as recommended [8]. Acid value and peroxide value were also determined as recommended method [9].

\subsection{Determination of $\mathrm{pH}$ value}

$2 \mathrm{~g}$ of the sample was poured into a clean dry $25 \mathrm{ml}$ beaker and $13 \mathrm{ml}$ of hot distilled water was added to the sample in the beaker and stirred slowly. It was then cooled in a cold-water bah to $25^{\circ} \mathrm{C}$. The $\mathrm{pH}$ electrode was standardized with buffer solution immersed into the sample and the $\mathrm{pH}$ value was read and recorded.

\subsection{In vitro antioxidant activity of coconut oil extract}

\subsubsection{Determination of total antioxidant capacity}

Total antioxidant activity was estimated by phosphomolybdenum assay [10] with slight modification. Methanol (1 ml) in the place of extract was used as the blank. The antioxidant activity was expressed as the number of gram equivalent of ascorbic acid. Ascorbic acid was used to prepare the standard calibration curve.

\subsubsection{Ferric reducing antioxidant power (frap) assay}

Ferric Reducing Antioxidant Power (FRAP) assay was done following a modified method of Benzie and Strain [11]. The reaction mixtures were incubated at $37{ }^{\circ} \mathrm{C}$ for $30 \mathrm{~min}$ and the increase in absorbance at $593 \mathrm{~nm}$ was measured. FeSO 4 was used for the calibration curve and ascorbic acid served as the positive control. FRAP values (expressed as mg Fe (II)/ $g$ of the extract) for the oils were then extrapolated from the standard curve.

\subsection{Determination of nutritional composition of coconut oil extract}

\subsubsection{Fatty acid composition}

Fatty acid methyl esters (FAME) of the oil samples were determined according to the method described by AOAC [12] with a slight modification. $50 \mathrm{mg}$ of the extracted fat content of the sample was saponified (esterified) for five (5) minutes at $95{ }^{\circ} \mathrm{C}$ with $3.4 \mathrm{ml}$ of the $0.5 \mathrm{M} \mathrm{KOH}$ in dry methanol. The mixture was neutralized by using $0.7 \mathrm{M} \mathrm{HCl} .3 \mathrm{ml}$ of the $14 \%$ boron triflouride in methanol was added. The mixture was heated for 5 minutes at the temperature of $90{ }^{\circ} \mathrm{C}$ to achieve complete methylation process. The fatty acid methyl esters were thrice extracted from the mixture with redistilled n-hexane. The content was concentrated to $1 \mathrm{ml}$ for gas chromatography analysis and $1 \mu \mathrm{l}$ was injected into the injection port of Gas Chromatography (HP 6890). Nitrogen was used as a carrier gas. The oven temperature was programmed from $(140-240){ }^{\circ} \mathrm{C}$ at $4{ }^{\circ} \mathrm{C} / \mathrm{min}$ with an initial hold at $140{ }^{\circ} \mathrm{C}$ for $5 \mathrm{~min}$. The identification of the peaks was performed by comparing the retention times with those of reference standards (Supelco Inc.). The results of fatty acids were expressed as relative area percentage.

\subsubsection{Phytosterol composition}

Quantification of phytosterol in the oil samples were determined according to the method described by AOAC [12]. 


\subsubsection{Determination of fat soluble vitamins}

Fat soluble vitamins were determined using high Performance Liquid Chromatography (HPLC) Dionex Technical Note 89. The mobile phase used was $\mathrm{CH}_{3} \mathrm{OH}: \mathrm{CH}_{3} \mathrm{CN}(8: 2, \mathrm{v} / \mathrm{v})$ and methyl tert-butyl ether (MTBE). Column used was acclaim PA, $3 \mathrm{um}, 120 \mathrm{~A}, 3.0 \times 150 \mathrm{~mm}$. Column temperature and injection volume were $25^{\circ} \mathrm{C}$ and $10 \mu \mathrm{l}$ respectively. Prior to injection, the solution were filtered through a $0.2 \mu \mathrm{m}$ filter (Millex-GN). The identification of the peaks was performed by comparing reference standards.

\section{Results}

Table 1 shows the physical properties; pH value, specific gravity, colour, odour, solubility and state of CP and HP at 30 ${ }^{\circ} \mathrm{C}$. Chemical properties; peroxide, iodine, free fatty acid, and saponification values of CP and HP coconut oils are reported on Table 2 . From the results, no statistical difference was observed between CP and HP coconut oils.

Table 1 Physical properties of CP and HP coconut oils

\begin{tabular}{lll}
\hline Indices & HP & CP \\
\hline pH Value & $4.40 \pm 0.00^{\mathrm{a}}$ & $5.00 \pm 0.00^{\mathrm{a}}$ \\
Specific Gravity (g) & $0.915 \pm 0.005^{\mathrm{a}}$ & $0.921 \pm 0.000^{\mathrm{a}}$ \\
Colour & Pale yellow & Clear white \\
Odour & Agreeable & Agreeable \\
State at $30^{\circ} \mathrm{C}$ & Liquid & Liquid \\
Solubility & Soluble in non-polar solvent & Soluble in non-polar solvent
\end{tabular}

HP: Hot pressed, CP: Cold pressed. Values are expressed as mean \pm SEM, $n=3$ replicates. Figures with different lowercase letters along the row represent significant difference between means at $p<0.05$.

Table 2 Chemical properties of CP and HP coconut oils

\begin{tabular}{lll}
\hline Indices & HP & CP \\
\hline Peroxide Value $\left(\mathrm{MeqO}_{2} / \mathrm{kg}\right)$ & $0.41 \pm 0.002^{\mathrm{a}}$ & $0.23 \pm 0.001^{\mathrm{a}}$ \\
Acid Value $(\mathrm{mg} \mathrm{KOH} / \mathrm{g})$ & $2.80 \pm 0.15^{\mathrm{a}}$ & $4.22 \pm 0.08^{\mathrm{b}}$ \\
Free Fatty Acid (\%) & $1.41 \pm 0.08^{\mathrm{a}}$ & $2.12 \pm 0.04^{\mathrm{a}}$ \\
Iodine Value $\left(\mathrm{gI}_{2} / 100 \mathrm{~g}\right)$ & $16.50 \pm 0.50^{\mathrm{a}}$ & $13.83 \pm 1.14^{\mathrm{a}}$ \\
Saponification Value $(\mathrm{mg} \mathrm{KOH} / \mathrm{g})$ & $284.00 \pm 0.70^{\mathrm{a}}$ & $282.61 \pm 0.07^{\mathrm{a}}$ \\
\hline
\end{tabular}

HP: Hot pressed, CP: Cold pressed. Values are expressed as mean \pm SEM, $n=3$ replicates. Figures with different lowercase letters along the row represent significant difference between means at $p<0.05$.

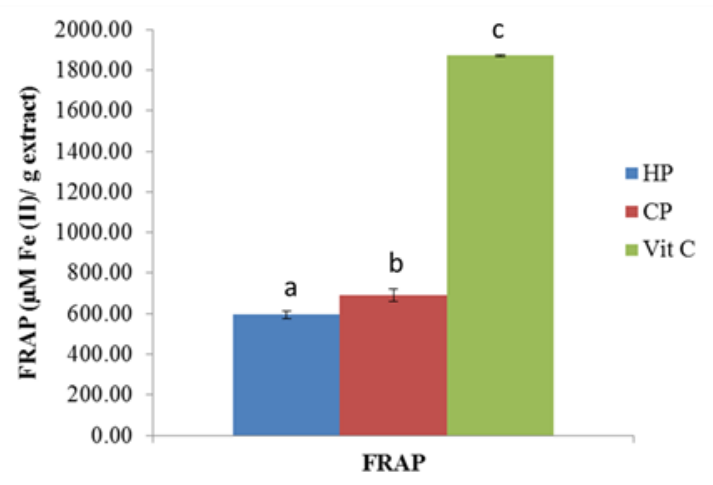

Figure 1 Ferric reducing antioxidant potential (FRAP) assessment of CP and HP coconut oils $\mathrm{HP}=$ Hot pressed, $\mathrm{CP}=$ Cold pressed. Values are expressed as mean $\pm \mathrm{SEM}, n=3$ replicates. Different lowercase letters represent significant difference between means at $p<0.05$. 
Ferric reducing and total antioxidant capacity of $\mathrm{CP}$ and $\mathrm{HP}$ are presented on Figures 1 and 2. CP has a better competitive value compared to standards used in the ferric reducing antioxidant assay. However, total antioxidant capacity of both oils is statistically the same.

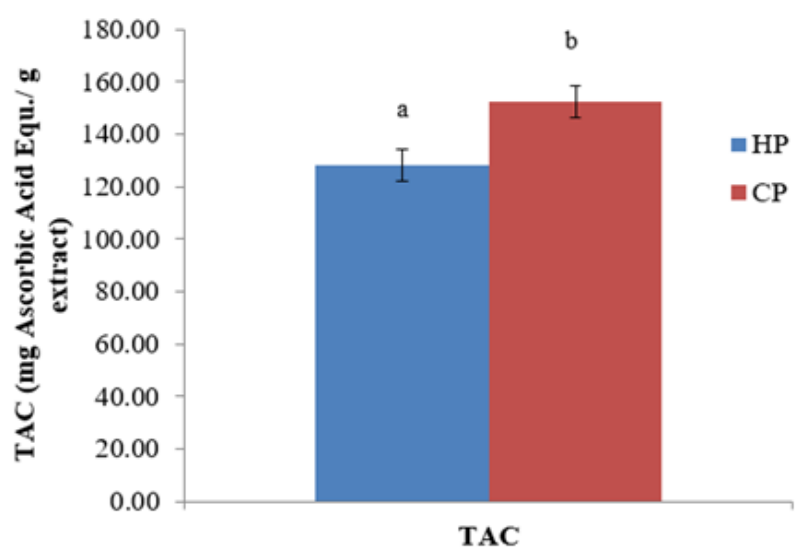

Figure 2 Total antioxidant capacity (TAC) assessment of CP and HP coconut oils $\mathrm{HP}=$ Hot pressed, $\mathrm{CP}=$ Cold pressed. Values are expressed as mean $\pm \mathrm{SEM}, n=3$ replicates. Different lowercase letters represent significant difference between means at $p<0.05$.

Fatty acid, phytosterol and vitamin compositions of CP and HP coconut oils are presented on Tables 3, 4 and 5. Figures $3 \mathrm{a}, 3 \mathrm{~b}, 4 \mathrm{a}$ and $4 \mathrm{~b}$ are gas chromatograms of the fatty acid profiles and sterol composition of CP and HP while Figures, $5 a$ and $5 b$ are HPLC chromatogram of vitamin composition of both oils.

Table 3 Fatty acid composition of cold pressed (CP) and hot pressed (HP) coconut oil

\begin{tabular}{lll}
\hline Fatty acid (\% composition) & CP & HP \\
\hline Caprylic acid; C8:0 & 5.45 & 5.77 \\
Capric acid; C10:0 & 6.39 & 7.72 \\
Lauric acid; C12:0 & 49.24 & 47.83 \\
Myristic acid; C14:0 & 17.01 & 16.33 \\
Palmitic acid; C16:0 & 9.53 & 9.94 \\
Palmitoleic acid; C16:1 & 0.00 & 0.00 \\
Margaric acid; C17:0 & 0.00 & 0.00 \\
Stearic acid; C18:0 & 3.08 & 2.06 \\
Oleic acid; C18:1 & 7.11 & 8.00 \\
Linoleic acid; C18:2 & 2.16 & 2.34 \\
Linolenic acid; C18:3 & 0.01 & 0.00 \\
Arachidic acid; C20:0 & 0.01 & 0.00 \\
Arachidonic acid; C20:4 & 0.00 & 0.00 \\
Behenic acid; C22:0 & 0.00 & 0.00 \\
Erucic acid; C22:1 & 0.00 & 0.00 \\
Lignoceric acid; C24:0 & 0.00 & 0.00 \\
SAFA & 90.71 & 89.65 \\
MUFA & 7.11 & 8.00 \\
PUFA & 2.17 & 2.34 \\
MCFA & 61.08 & 61.32 \\
\hline
\end{tabular}

FA = fatty acids, SAFA = saturated fatty acid, MUFA = monounsaturated fatty acid, PUFA = polyunsaturated fatty acid and MCFA =medium chain fatty acid. 

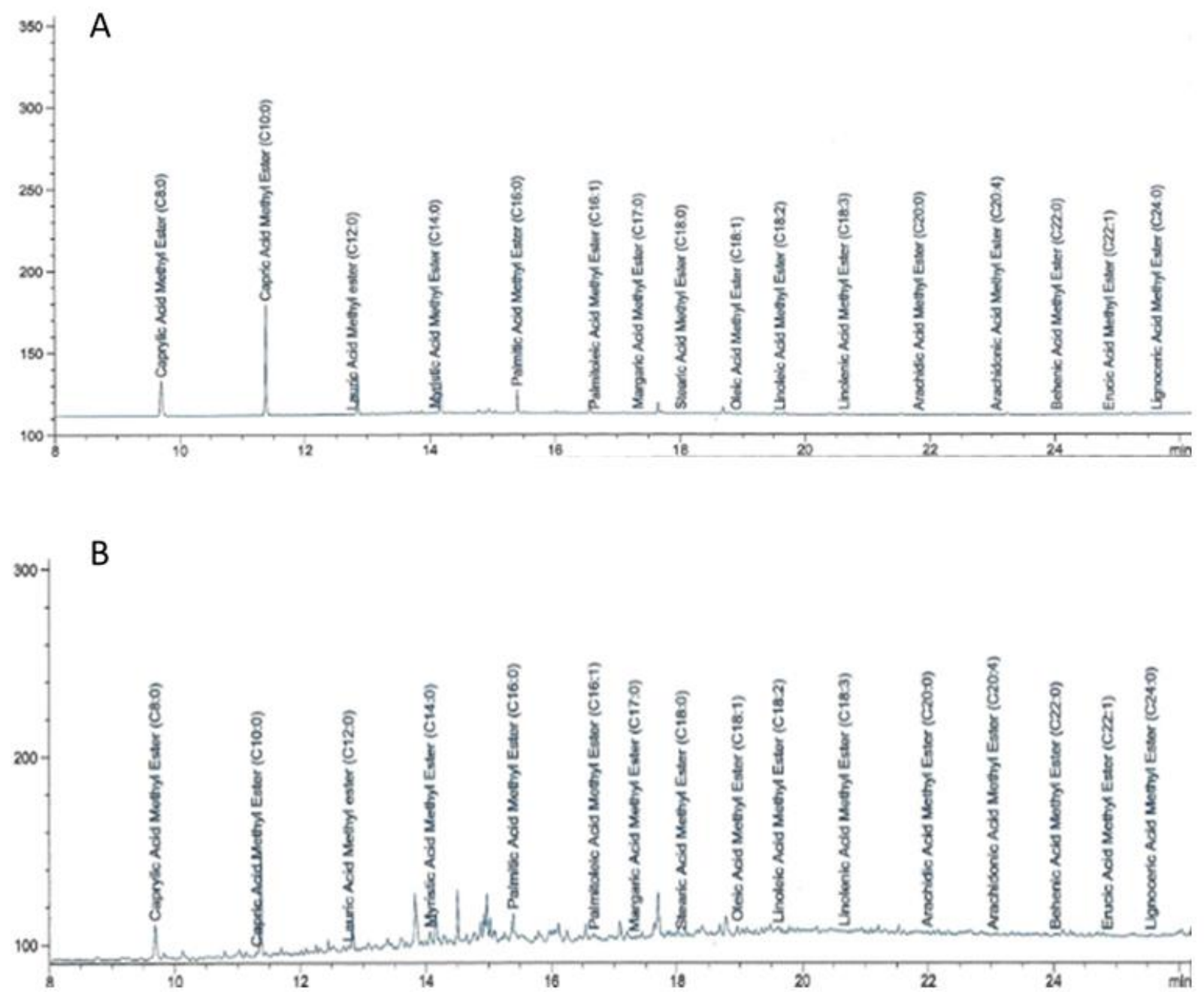

Figure 3 GC-Chromatogram of the fatty acid profile of cold (A) and hot (B) pressed coconut oil

Table 4 Phytosterol composition of cold pressed (CP) and hot pressed (HP) coconut oil

\begin{tabular}{lll}
\hline Sterols $\mathbf{( m g} / \mathbf{~ 1 0 0 ~ g ) ~}$ & Cold pressed & Hot pressed \\
\hline Campesterol & 7.68 & 5.28 \\
Stigmasterol & 15.33 & 16.98 \\
$\Delta-5$-Avenasterol & 14.56 & 12.50 \\
$\beta$-Sitosterol & 61.67 & 68.00 \\
Ergosterol & $1.83 \times 10^{-3}$ & $2.49 \times 10^{-3}$ \\
Cholestanol & $4.04 \times 10^{-6}$ & $9.13 \times 10^{-4}$ \\
Cholesterol & $1.90 \times 10^{-4}$ & $2.09 \times 10^{-2}$ \\
\hline Total & 99.24 & 102.79 \\
\hline
\end{tabular}


Idu et al. / GSC Biological and Pharmaceutical Sciences 2018, 05(01), 056-066
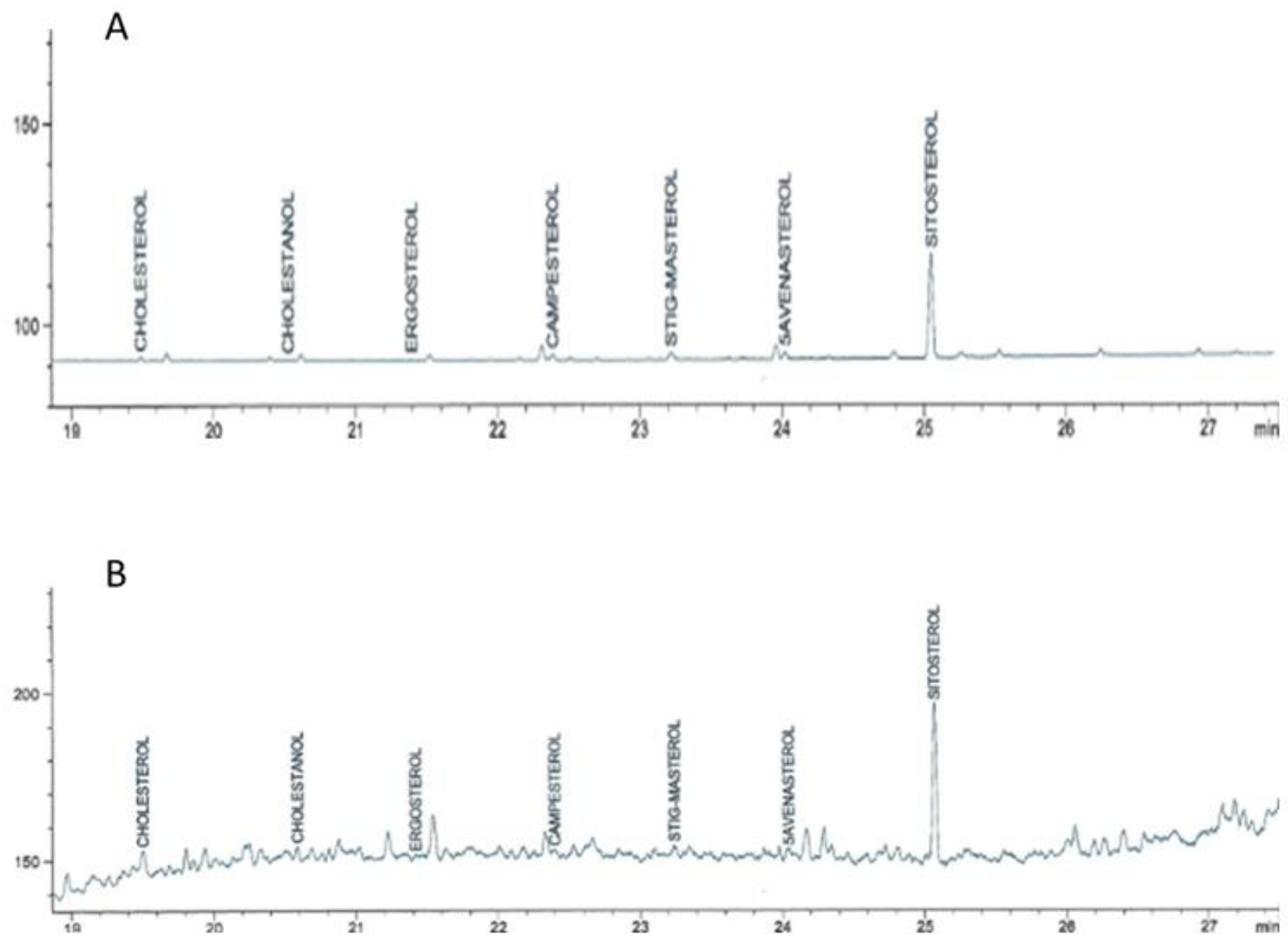

Figure 4 Gas Chromatogram of sterol composition of cold (A) and hot (B) pressed coconut oil

Table 5 Vitamin composition of cold pressed (CP) and hot pressed (HP) coconut oil

\begin{tabular}{lll}
\hline Vitamins $(\mathrm{mg} / 100 \mathrm{~g})$ & $\mathrm{CP}$ & $\mathrm{HP}$ \\
\hline $\mathrm{A}$ & $2.10 \times 10^{-7}$ & $3.59 \times 10^{-7}$ \\
$\mathrm{D}$ & $1.02 \times 10^{-7}$ & $1.23 \times 10^{-7}$ \\
$\mathrm{E}$ & $4.39 \times 10^{-1}$ & $4.97 \times 10^{-1}$ \\
$\mathrm{~K}$ & $3.57 \times 10^{-4}$ & $4.68 \times 10^{-4}$ \\
Total & $4.39 \times 10^{-1}$ & $4.98 \times 10^{-1}$ \\
\hline
\end{tabular}



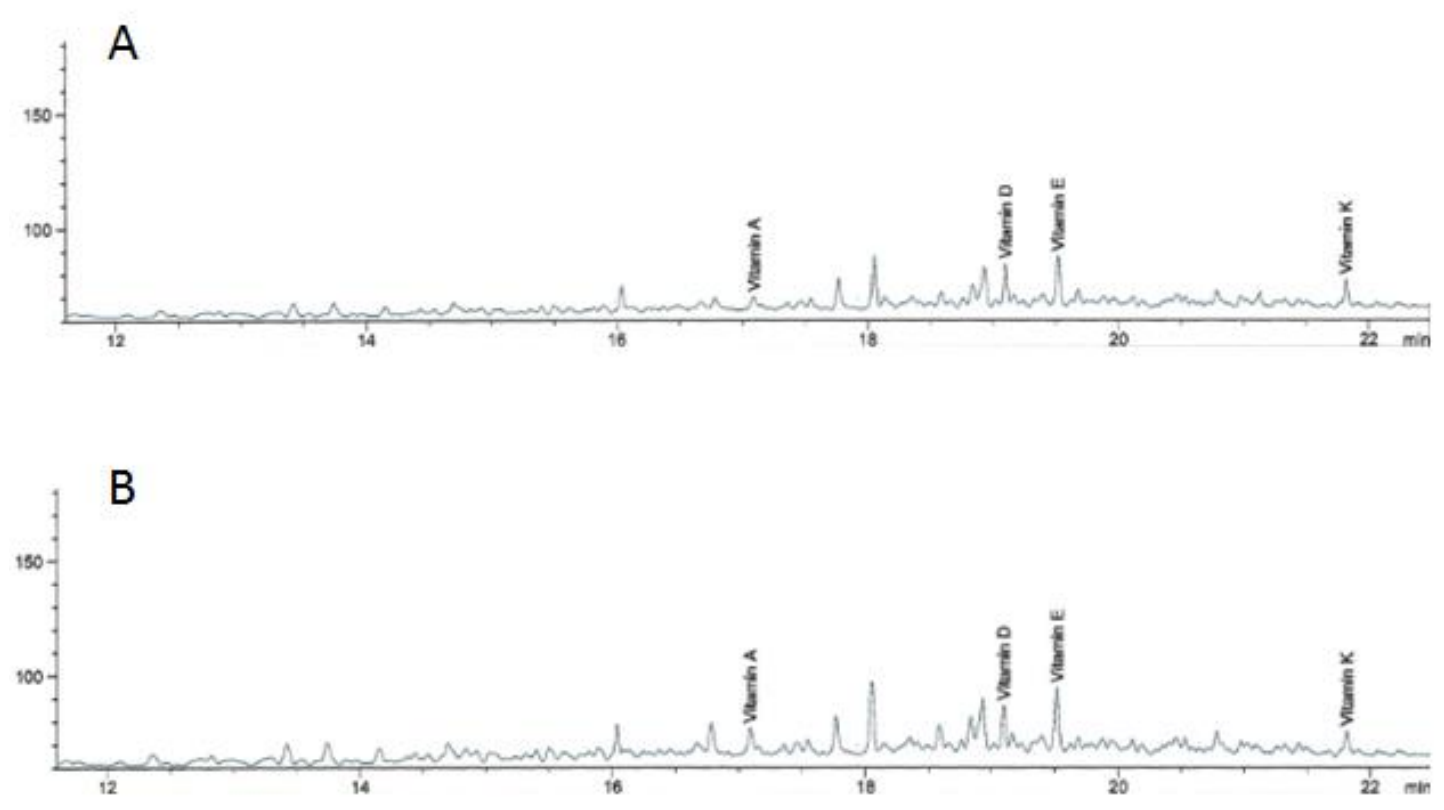

Figure 5 HPLC Chromatogram of vitamin composition of cold (A) and hot (B) pressed coconut oil

\section{Discussion}

The physicochemical studies revealed that the colour of hot pressed (HP) oil was pale yellow while that of the cold pressed (CP) was clear white. This colour seen in the hot pressed may have been induced by the heat used during extraction (Table 1). Both oils had agreeable flavour and were also liquid at room temperature. There was no significant difference in the specific gravity of both oils. The specific gravity of the oils HP $(0.915 \pm 0.005)$ and CP $(0.921 \pm 0.000)$ indicate that the oils are less dense than water and they also compare favourably with the range of $0.90-0.93$ reported for other oils from some common plants in Nigeria [13,14,15] and unrefined coconut oils from India [5].

Acid value is used as an indicator for edibility of oil and suitability for use in the paint industry [16]. From Table 2 in the present study, HP coconut oil had a significantly lower acid value $(2.80 \pm 0.15 \mathrm{mg} \mathrm{KOH} / \mathrm{g})$ when compared to the $\mathrm{CP}$ coconut oil ( $4.22 \pm 0.08 \mathrm{mg} \mathrm{KOH} / \mathrm{g})$ indicating the lower level to which the glycerides in the oil had been decomposed by lipase action [17]. The acid value of the oils fell within allowable limits for crude coconut oil as given by the Caricom regional organization for standard quality [18], so CP and HP coconut oils can be declared edible. These values also compared favourably with $2.06 \pm 0.32 \mathrm{mg} \mathrm{NaOH} \mathrm{g}^{-1}$ and $6.36 \pm 0.32 \mathrm{mg} \mathrm{NaOH} \mathrm{g}^{-1}$ reported for Cocos nucifera extracted by the soxhlet and mechanical method respectively [19]. However, the values were lower than $11.31 \mathrm{mg} \mathrm{NaOH} \mathrm{g}^{-1}$ and $11.46 \mathrm{mg} \mathrm{NaOH} \mathrm{g}{ }^{-1}$ reported for Cocos nucifera and Persea gratesima respectively [16].

Free fatty acid (FFA) content is an indicator of the hydrolytic rancidity of oils which causes an undesirable aroma and flavour in oils. FFA may be liberated by lipase activity of some fungal strains (such as Aspergillus flavus) which attack copra and wet coconut kernel [20]. FFA value of CP $(2.12 \pm 0.04 \%)$ was not significantly different from that of HP (1.40 $\pm 0.08 \%$ ) and they were within the required range of FFA expected in crude coconut oil [18]. The lower FFA of HP coconut oil is an indication that it is of better quality than CP coconut oil (Table 3). These values compare favourably to those reported for Cocos nucifera $2.75 \pm 4.5 \%$ [15], palm kernel oil $1.35 \pm 0.15 \%$ [15], Cissus aralioides seed oil $2.13 \pm$ 0.025 [21] and Cocos nucifera $4.80 \pm 0.06 \%$ [16].

The unsaturated fatty acids present in oils easily react with atmospheric oxygen and form hydro-peroxides. Peroxide value (PV) is an indication of deterioration and also the initial stages of oxidation in oil. Peroxide values between 20 and $40\left(\mathrm{MeqO}_{2} / \mathrm{kg}\right)$ result to rancid taste [22]. Normally coconut oils exhibit high oxidative stability due to the presence of large amounts of saturated fatty acids (>91\%) [4]. On Table 2, HP oil had an insignificantly higher value for PV $(0.41 \pm$ $\left.0.002 \mathrm{MeqO}_{2} / \mathrm{kg}\right)$ than $\mathrm{CP}\left(0.23 \pm 0.001 \mathrm{MeqO}_{2} / \mathrm{kg}\right)$. This indicates that oxidative deterioration was higher in HP when compared to CP coconut oil. The lower PV of CP oil gives an insight to its freshness and the higher PV observed in HP may be caused by the method of extraction as well as the quality of the coconut meat used. The values obtained for the oils falls within the range of $0.21-14.3 \mathrm{MeqO}_{2} / \mathrm{kg}$ reported for different oils in the Nigerian market $[3,14,15,16,19]$. 
Iodine value (IV) is a measure of the degree of unsaturation in oils. Iodine values above 100 are classified as drying while those below are classified as non-drying [23]. The iodine value of $\mathrm{HP}$ oil was $16.50 \pm 0.50 \mathrm{gI}_{2} / 100 \mathrm{~g}$ while CP oil was $13.83 \pm 1.14 \mathrm{gI}_{2} / 100 \mathrm{~g}$. Although both oils maybe classified as non-drying, HP oil had a higher iodine value when compared to CP oil and this was not significant. The increase in iodine value may be due to the slightly higher number of unsaturated fatty acids HP possesses. The iodine value in this study was higher than some reported values for Cocos nucifera. These values include $9.60 \pm 0.02$ Akubugwo et al. [16], cold pressed virgin coconut oil $7.61 \pm 0.03$ Arumugam et al. [24] and $8.5 \pm 1.5$ Amira et al. [15]. However, it was lower than $46.8 \pm 0.63$ reported for Cocos nucifera kernel oil [3]. The relatively low iodine value indicates that both oils have low content of unsaturated fatty acids and may be useful in soap making and as lubricant aside its edible uses.

The saponification value gives an ideal of the molecular weight, level of unsaturation and approximate chain length of the oil. The saponification value of hot pressed and cold pressed oil was found to be $284.00 \pm 0.70 \mathrm{mg} \mathrm{KOH} / \mathrm{g}$ and 282.61 $\pm 0.07 \mathrm{mg} \mathrm{KOH} / \mathrm{g}$ respectively and they were not significantly different. This suggests that cold pressed oil extract has a higher molecular weight. This is because, the extract with lower saponification value have higher molecular weight [14]. Also, it can be inferred that HP oil has a higher level of unsaturated fatty acids than CP oil. The saponification values gotten for CP and HP oil were higher than $248-265 \mathrm{mg} \mathrm{KOH} / \mathrm{g}$ which is the prescribed limit according to Codex Standard Specification for coconut oil [25]. The high saponification value may be connected to the nature of the oils and the metallic ion present among other factors $[26,27]$.

One of the methods used in measuring the antioxidant property of samples is the 'total antioxidant capacity' assay. In the present study, there was no significant difference in the antioxidant capacity of CP oil (152.54 $\pm 6.00 \mathrm{mg}$ ascorbic acid equ. /g extract) when compare to HP oil (128.44 $\pm 6.10 \mathrm{mg}$ ascorbic acid equ. /g extract). However, the antioxidant capacity of CP oil was slightly higher than that of HP oil. Method of extraction of HP oil may have degraded some phytochemicals and as such resulted in a slight decrease of its antioxidant strength.

FRAP assay is reproducible and linearly related to the molar concentration of the antioxidant(s) present in the biological sample [28]. It is a fast, simple and precise assay. CP oil (692.50 $\pm 30.50 \mu \mathrm{M} \mathrm{Fe}$ (II) /g extract) had a significantly higher FRAP value when compared to HP oil ( $594.00 \pm 17.67 \mu \mathrm{M}$ Fe (II) /g extract). Quality of raw material, storage condition as well as method of extraction may have resulted in this difference. Also, there was a significant difference between these values and the standard ascorbic acid (1872.33 $\pm 5.55 \mu \mathrm{M}$ Fe (II) /g extract).

Medium chain fatty acids (MCFA) have carbon atom ranging from 6-12. They are easily digested, absorbed and used as a source of energy rather than stored in the body. Lauric acid (C12:0) is the major fatty acid present in coconut oil. Fatty acid compositions of hot and cold pressed coconut oils are shown on Table 3. CP oil had slightly higher lauric acid (49.24\%) value when compared to HP oil (47.83\%). The values observed in both oils were comparable with the results reported by Bhatnagar et al. [29] 49.1\%, Srivastava et al. [30] 48.50\% and Essien et al. [31] 45.02\%. Also, they were within the prescribed range for lauric acid (45.1 - 53.2\%) in coconut oil as reported by Codex [25]. Closely following lauric acid in terms of abundance was myristic acid which was $17.01 \%$ and $16.33 \%$ for CP and HP oil respectively. Palmitic acid, capric acid, caprylic acid, oleic acid and linoleic acid were higher in HP oil when compared to CP and it was observed to be $9.94 \%, 7.72 \%, 5.77 \%, 8.00 \%$ and $2.34 \%$ respectively. While in CP oil, they were palmitic acid (9.53\%), capric acid (6.39\%), caprylic acid (5.45\%), oleic acid (7.11\%) and linoleic acid (2.16\%). Palmitoleic acid, margaric acid, linolenic acid, arachidic acid, arachidonic acid, behenic acid, erucic acid and lignoceric acid in both oil extracts were in trace amounts and they ranged from $0.0005-0.01 \%$. The fatty acids present in both oil extracts were within the prescribed range for fatty acids in coconut oil as reported by Codex [25].

Coconut oil contains high amounts of saturated fatty acids (SAFA) as compared to other edible oils. This high SAFA composition provides protection to coconut oil against oxidative rancidity [4]. SAFA was highest in CP oil (90.71\%) when compared to HP oil (89.65\%) and medium chain fatty acid made up the major part of the SAFA. However, HP oil had a slightly higher monounsaturated fatty acids (MUFA) $8.00 \%$, polyunsaturated fatty acids (PUFA) $2.34 \%$ and medium chain fatty acids (MCFA) $61.32 \%$ compared to CP oil which had MUFA 7.11\%, PUFA $2.17 \%$ and MCFA 61.08\%. Method used in the extraction of HP oil as well as nature of raw materials and storage method used may be responsible for the slight decrease in SAFA and increase in MUFA and PUFA when compared to CP oil.

Phytosterols are cholesterol-like molecules absorbed only in trace amounts but inhibit the absorption of intestinal cholesterol including recirculating endogenous biliary cholesterol, a key step in cholesterol elimination [32]. Phytosterols, primarily stigmasterol, $\beta$-sitosterol and campesterol are integral natural components of plant cell membranes that are abundant in vegetable oils, nuts, seeds, and grains [33]. Result of the phytosterol composition is shown on Table 4. Total phytosterol content was higher in HP oil $(102.79 \mathrm{mg} / 100 \mathrm{~g})$ when compared to CP oil (99.24 $\mathrm{mg} / 100 \mathrm{~g}$ ). $\beta$-Sitosterol was the major phytosterol found in both oil extracts. HP oil had the largest amount of $\beta$-sitosterol 
Idu et al. / GSC Biological and Pharmaceutical Sciences 2018, 05(01), 056-066

(68.00 mg/100g) when compared to CP oil (61.67 mg/100g). Stigmasterol was also higher in HP oil (16.98 mg/100g) when compared to CP oil (15.33 mg/100g). However, $\Delta-5$-avenasterol and campesterol were higher in CP oil extract and it was observed to be $14.56 \mathrm{mg} / 100 \mathrm{~g}$ and $7.68 \mathrm{mg} / 100 \mathrm{~g}$ respectively. While in HP oil, they were $\Delta-5$-avenasterol $12.50 \mathrm{mg} / 100 \mathrm{~g}$ and campesterol $5.28 \mathrm{mg} / 100 \mathrm{~g}$. Ergosterol, cholestanol and cholesterol in both oil extracts were very low and ranged from $0.00-0.012 \mathrm{mg} / 100 \mathrm{~g}$. Sterol levels in this study were found higher than the findings of Verleyen $e t$ al. [34], who determined $48.6 \mathrm{mg} / 100 \mathrm{~g} \beta$-sitosterol and $12.5 \mathrm{mg} / 100 \mathrm{~g}$ stigmasterol in crude coconut oil. Also, in Verleyen et al. [35] study, $\Delta$-5-avenasterol was not detected and campesterol $7.8 \mathrm{mg} / 100 \mathrm{~g}$ was higher than the reported values in this study. Factors such as genetic species, growing and storage conditions influence of the refining process, and specificity of the analytical method applied may be responsible for this variation in result [35].

Vitamins are group of organic nutrients required in small amount for a variety of biochemical functions as well as general well-being. Some vitamins cannot be synthesized in the body while others are not synthesized in adequate amount, hence the need to supplement via diet. Table 5 shows the vitamin composition of the two oil extracts. Total vitamin content was higher in HP oil $(0.498 \mathrm{mg} / 100 \mathrm{~g})$ when compared to CP coconut oil $(0.439 \mathrm{mg} / 100 \mathrm{~g})$. Vitamin E was the most abundant vitamin in both oil extracts while vitamin $\mathrm{A}, \mathrm{D}$ and $\mathrm{K}$ were in trace amounts. Vitamin $\mathrm{E}$ was higher in HP oil ( $0.497 \mathrm{mg} / 100 \mathrm{~g})$ when compared to CP oil $(0.439 \mathrm{mg} / 100 \mathrm{~g})$. Method of extraction may have been responsible for this difference. It is also possible that auto-oxidation occurred in CP oil since vitamin E is consumed by auto-oxidation of oils [36]. These values for vitamin E were lower than $1.9 \pm 1.1 \mathrm{mg} / 100 \mathrm{~g}$ reported by Kumar and Krishna, [4] for average value of $\alpha$-tocopherol in unrefined coconut oil. However, they were within the prescribed range (not detected $-1.7 \mathrm{mg} / 100 \mathrm{~g}$ ) of $\alpha$-tocopherol in coconut oil as reported by Codex [25].

\section{Conclusion}

The result showed that the hot pressed (HP) oil had better physicochemical properties than the cold pressed (CP) oil except that it had a higher peroxide value. Also, HP oil had a fairly higher phyto-nutritional composition than the CP oil. However, CP oil had a slightly higher antioxidant property. These findings would be useful in nutraceuticals because of the vitamin, phytosterol and fatty acid profile in both oil extracts which seems to have considerable health benefits. Also, most of the findings compare favourably with other commonly used oils. Thus, the usage of cold and hot pressed coconut oils should be encouraged.

\section{Compliance with ethical standards}

\section{Acknowledgments}

The authors acknowledge $S f k$ coconut oil for the coconut oil samples. The authors also acknowledge the support of the laboratory technologists that helped implement this project.

\section{Disclosure of conflict of interest}

The authors humbly declare no conflicts of interest regarding publishing this research and that this research was entirely funded by the authors.

\section{References}

[1] Olaniyi AP, Babalola 00 and Oyediran AM. (2014). Physicochemical properties of palm kernel oil. Research Journal of Biological Sciences, 6(5), 205-207.

[2] Kappally S, Shirwaikar A and Shirwaikar A. (2015). Coconut oil - a review of potential applications. Hygeia Journal of Drug and Medicines, 7(2), 34-41.

[3] Sani I, Owoade C, Abdulhamid A, Fakai IM and Bello F. (2014). Evaluation of physicochemical properties, phytochemicals and mineral composition of Cocos nucifera L. (Coconut) kernel oil. International Journal of Advanced Research in Chemical Sciences, 1(8), 22-30.

[4] Kumar PKP and Krishna AGG. (2015). Physicochemical characteristics of commercial coconut oils produced in India. Grasas y Aceites, 66(1), 1-15.

[5] Gopala KAG, Gaurav R, Ajit SB, Prasanth KPK and Preeti C. (2010). Coconut oil: chemistry, production and its applications - a review. Indian Coconut Journal, 15-27. 
Idu et al. / GSC Biological and Pharmaceutical Sciences 2018, 05(01), 056-066

[6] Conrado SD. (2003). Coconut oil: Atherogenic or Not? (What therefore causes Atherosclerosis?). Philippine Journal of Cardiology, 31(3), 97-104.

[7] Pearson D. (1980). The chemical Analysis of Food. Scheckwahtong Printing press.

[8] AOCS (1992). Official methods and recommended practices of the American Oil Chemists Society (4th ed.), Champaign, American Oil Chemists' Society, USA.

[9] AOAC Official methods of analysis. (1997). Association of Official Analytical Chemists.17th Edition. Washington DC.

[10] Prieto P, Pineda M and Anguilar M. (1999). Spectrophotometric quantitation of antioxidant capacity through the formation of a Phosphomolybdenum Complex: Specific application to the determination of Vitamin E. Analytical Biochemistry, 269, 337-341.

[11] Benzie IFF and Strain JJ. (1996). The ferric reducing ability of plasma (frap) as a measure of "antioxidant power": The FRAP assay. Analytical Biochemistry, 239, 70-76.

[12] AOAC (2000). Official Methods of Analysis 17th Edition, Association of Official Agric. Chem. Washington D.C. 1970.

[13] Ajayi IA and Oderinde RA. (2002). Studies on the oil characteristics of Dacryodes edulis pulp and seeds. Discovery Innovations, 14, 20-24.

[14] Okpashi VE, Ogugua VN, Ugian EA and Njoku OU. (2013). Physico-chemical properties of fluted pumpkin (telfiariaoccidentalis hook f) seeds. The International Journal of Engineering Sciences, 2(9), 36-38.

[15] Amira PO, Babalola 00 and Oyediran AM. (2014). Physicochemical Properties of Palm Kernel Oil. Current Research Journal of Biological Sciences, 6(5), 205-207.

[16] Akubugwo IE, Chinyere GC and Ugbogu AE. (2008). Comparative Studies on Oils from Some Common Plant Seeds in Nigeria. Pakistan Journal of Nutrition 7(4), 570-573.

[17] Pearson, D.M. (1975). The Chemical Analysis of Food. 5th Edn., AVI Publishers, West Port.

[18] CARICOM Regional Organisation for Standards and Quality; specifications for coconut oil. (2016). https://www.crosq.org

[19] Obasi NA, Ukadilonu J, Eze E, Akubugwo EI and Okorie U.C. (2012). Proximate composition, extraction, characterization and comparative assessment of coconut (Cocos nucifera) and melon (Colocynthis citrullus) seeds and seed oils. Pakistan Journal of Biological Sciences, 15(1), 1-9.

[20] Hoover R, Laurentius SF and Gunetileke KG. (1973). Spoilage of coconut oil purification and properties of a fungal lipase that attacks coconut oil. Journal of the American oil chemists', 50(3), 64-67

[21] Oduje AM, Awode A, Edah A and Sagay I. (2015). Characterization and phytochemical screening of n-hexane oil extract from Cissus aralioides seeds. International Journal of Scientific and Engineering Research, 6(1), 112-116.

[22] Pearson D. (1976). The chemical Analysis of Food Churchill, livingstone, pp: 488-496.

[23] Julius K, Umenger N and Ayangealumun I. (2013). Effects of extraction methods on the yield and quality characteristics of oils from shea nut. Journal of Food Resource Science, 2(1), 1 -12.

[24] Arumugam M, Raman M and Eagappan K. (2014). Cold pressed virgin coconut oil from full fat coconut flakes a functional oil. International Journal of Pharmacy and Pharmaceutical Sciences, 6(6), 186-190.

[25] Codex Alimentarius. (2003). Codex standard for named vegetable oils. Codex Stan. 210, Pp 5-13.

[26] Esuoso K, Lutz H, Kutubuddin M and Bayer E. (1998). Chemical composition and potential of some under listed biomass, I. fluted pumpkin (Telfaria occidentalis). Journal of Food Chemistry, 61(4), 487-492.

[27] Nkafamiya II, Aliyu BA, Manji AJ and Moddibo UU. (2007) Evaluation of deterioration of traditionally produced groundnut oil on storage. Journal of Chemical Society of Nigeria, 32(1), 137-142.

[28] Omoregie ES, Oriakhi K, Oikeh EI, Okugbo OT and Akpobire D. (2014). Comparative studies of phenolic content and antioxidant activity of the leaf extracts of Alstonia boonei and Eupatorium odoratum. Nigerian Journal of Basic and Applied Sciences, 22(3 \& 4), 91-97. 
[29] Bhatnagar AS, Prasanth KPK, Hemavathy J and Gopala KAG. (2009). Fatty acid composition, oxidative stability, and radical scavenging activity of vegetable oil blends with coconut oil. Journal of the American Oil Chemists' Society, 86, 991-999.

[30] Srivastava Y, Semwal AD and Majumdar A. (2016). Quantitative and qualitative analysis of bioactive components present in virgin coconut oil. Cogent Food and Agriculture, 2, 1-13.

[31] Essien NM, Ofem OE and Bassey SC. (2014). Comparative physical characterization, physico-chemical and fatty acid composition of some edible vegetable oils. Journal of Advances in Biology and Biotechnology, 1(1), 30-39.

[32] Daksha A, Jaywant P, Bhagyashree C and Subodh P. (2010). Estimation of sterols content in edible oil and ghee samples. International Journal of Pharmaceutical Science Review and Research, 5(1), 135-137.

[33] Ryan E, Galvin K, O'Connor TP and Maguire AR. (2007). Phytosterol, squalene, tocopheral content and fatty acid profile of selected seeds, grains, and legumes. Plant Foods for Human Nutrition, 62, 85-91.

[34] Verleyen T, Forcades M, Verhe R, Dewettinck K, Huyghebaert A and De Greyt W. (2002). Analysis of free and esterified sterols in vegetable oils. Journal of the American Oil Chemists' Society, 79(2), 117-122.

[35] Piironen V, Lindsay DG, Miettinen TA, Toivo J and Lampi AM. (2000). Plant sterols: biosynthesis, biological function and their importance to human nutrition. Journal of the Science of Food and Agriculture, 80: 939-966.

[36] Ingold, K.U., Bowry, V.W., Stocker, R. and Walling, C. (1993). Autoxidation of lipids and antioxidation by alphatocopherol and ubiquinol in homogeneous solution and in aqueous dispersions of lipids: Unrecognized consequences of lipid particle size as exemplified by oxidation of human low density lipoprotein. Proceedings of the National Academy of Sciences of the United States of America, 90(1), 45-49.

\section{How to cite this article}

Idu M, Ovuakporie-Uvo 0, Omoregie ES and Omosigho M. (2018). Physicochemical properties, antioxidant activity and phyto-nutritional composition of cold and hot pressed coconut oils. GSC Biological and Pharmaceutical Sciences, 5(1), 56-66. 